$\begin{array}{cc}\text { ACADEMIA ROMÂNĂ } & \text { Rev. Roum. Chim., } \\ \text { 2019, 64(9), 791-799 }\end{array}$

\title{
SELECTIVE MEASUREMENT OF EUROPIUM(III) IN SOLUTIONS USING A SENSOR WITH POLYMERIC MEMBRANE
}

\author{
Arezoo GHAEMI, Haman TAVAKKOLI and Fatemeh Hasan GHAHVAROKHI \\ Department of Chemistry, Ahvaz Branch, Islamic Azad University, Ahvaz, Iran
}

Received November 28, 2018

\begin{abstract}
Kryptofix 21 was found to be a suitable neutral ionophore for the preparation of a highly selective europium (III) membrane sensor. Polyvinyl chloride (PVC)-based membranes of kryptofix 21 with sodium tetraphenylborate (NaTPB) as an anionic additive, and dibutyl phthalate (DBP), nitrobenzene (NB), dioctyl phtalate (DOP) and dioctyl sebacate (DOS) as plasticizer were prepared and investigated as Eu (III) sensors. A membrane composed of kryptofix 21-PVC-NaTPB-DOS with the ratio of 7.0:30.0:2.0:61.0 mg works well over a wide linear concentration range $\left(1.0 \times 10^{-6}\right.$ to $\left.1.0 \times 10^{-1} \mathrm{M}\right)$ with a Nernstian slope of $21.8 \pm 0.1$ $\mathrm{mV} /$ decade of activity, between $\mathrm{pH}$ values of 2.0-12.0. The proposed sensor had a fast response time of $15 \mathrm{~s}$ and good reproducibility. The detection limit of the sensor was calculated to be $8.2 \times 10^{-7} \mathrm{M}$. The proposed electrode shows excellent discrimination toward Eu (III) ions with regard to some alkali, transition and heavy metal cations. To test the analytical applicability of the sensor, it was used as an indicator electrode for the titration of Eu (III) ions with EDTA. In addition, this sensor was successfully used for determination of Eu (III) in real samples.
\end{abstract}

\section{INTRODUCTION}

The rare earth elements are considered only slightly toxic according to the Hodge-Sterner classification system and can be handled safely with ordinary care. ${ }^{1}$ The toxicity of rare earth elements in humans has not been reported, but extensive tests of toxicity have been made on animals.

Europium is classified as rare earth family. Europium has a strong tendency to absorb neutrons, making it useful in nuclear power production. A nuclear power plant produces electricity from the energy released by nuclear fission. Slow-moving neutrons collide with uranium or plutonium atoms, breaking them apart and releasing energy as heat. The amount of energy produced in a nuclear power plant is controlled by the number of neutrons present. Europium phosphors are used in television tubes to give a bright red color and as an activator for yttrium-based phosphors. For powerful street lighting a little europium is added to mercury vapor lamps to give a more natural light. A salt of europium is used for newer phosphorescent powder and paints. Europium salts could be toxic by ingestion, but their toxicity has not been fully investigated. $^{2}$ Because of industrial use of europium, on one hand, and its hazardous effects, on the other, many studies have been carried out on the development of methods for europium determination.

The senses are keys to life as they permit the perception of outside stimuli. The commonly cited ones include hearing, touch, sight, taste, and smell, allow humans to obtain physical and chemical information about their environment. Attempts to use the same principles and build instrumentation that measures such parameters have resulted in sensors that measure physical parameters, such as

\footnotetext{
${ }^{*}$ Corresponding author: arezooghaemi@yahoo.com; Fax: +98 611 34435288; Tel: +98 61134457612
} 
pressure, temperature, and the intensity of light, as well as chemical sensors that can be used to measure the concentration of specific chemical species in air and water. Chemical sensors are miniaturized analytical devices, which can deliver real-time and on-line information on the presence of specific compounds or ions in complex samples. Usually an analyte recognition process takes place followed by the conversion of chemical information into an electrical or optical signal. Among various classes of chemical sensors, ionselective electrodes (ISEs) are the most frequently used potentiometric sensors during laboratory analysis as well as in industry, process control, physiological measurements and environmental monitoring. ISEs have shown to be very effective tools for the analysis of a wide variety of cations, anions, and molecules. They are selective methods for monitoring and determination of rare earth elements. They offer advantages of low cost, portability, selectivity and simple function. They also provide an analysis method without destruction of sample. In addition, they can be used in complex matrix of samples. ${ }^{3-7}$ At the time of this writing, more than 20,000 publications related to ion-selective electrodes have been published, with approximately two new ones per day in recent years. $^{8-12}$

This work aims to describe the novel fabrication of a highly selective and sensitive europium (III) PVC membrane sensor, based on 1,4,10-trioxa-7,13diazacyclopentadecane (kryptofix 21) (Fig. 1) as an excellent ionophore, for the potentiometric determination of $\mathrm{Eu}$ (III) ion.

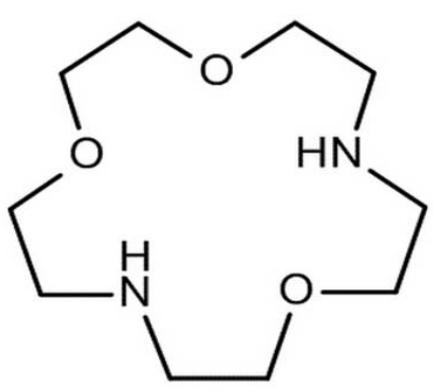

Fig. 1 - Structure

of 1,4,10-trioxa-7,13-diazacyclopentadecane (kryptofix 21).

\section{EXPERIMENTAL}

\section{Reagents}

Reagent grade dibutyl phthalate (DBP), dioctyl sebacate (DOS), nitrobenzene (NB), dioctyl phthalate (DOP), sodium tetraphenylborate (NaTPB), tetrahydrofuran (THF), 1,4,10- trioxa-7,13-diazacyclopentadecane (kryptofix 21), high relative molecular weight poly(vinyl chloride) (PVC), ethylenediaminetetraacetic acid disodium salt, nitric acid, sodium hydroxide and nitrate salts of all cations were purchased from Merck chemical company and were of the highest purity available and used as received.

\section{Electrode preparation}

The electrodes were prepared from graphite bars $(3 \mathrm{~mm}$ diameter and $50 \mathrm{~mm}$ long). The graphite bars were polished and put in a concentrated $\mathrm{HNO}_{3}$ solution overnight to clean the surface of the electrodes. Then, the bars were rinsed with THF and once again polished and washed with distilled water and allowed to dry. A shielded copper wire was glued to one end of the graphite bar and the bar was inserted into the end of a polyethylene tube. A mixture of PVC, plasticizer, ionophore (kryptofix 21) and the membrane additive (NaTPB) to give a total mass of $100 \mathrm{mg}$ was dissolved in about $2 \mathrm{~mL}$ of THF and the solution was mixed well. The graphite bar was coated by dipping into the membrane solution for a few seconds and allowed to dry overnight. The electrode was conditioned for $24 \mathrm{~h}$ in $1.0 \times 10^{-3} \mathrm{M}$ europium (III) nitrate solution and stored in mild concentration solutions $\left(1.0 \times 10^{-5} \mathrm{M}\right)$ of europium (III) nitrate, when not in use. The coating solutions were stable for several days and could be used for construction of new membranes.

\section{Emf measurements}

All the potential measurements were carried out using a $713 \mathrm{pH}-\mathrm{mV}$ meter (Metrohm, Switzerland) at laboratory ambient temperature. All the emf measurements were carried out versus an $\mathrm{Ag} / \mathrm{AgCl}$ double junction reference electrode (Azar electrode, Iran) and were carried out with the following cell assemblies:

\section{$\mathrm{Ag} / \mathrm{AgCl} ; \mathrm{KCl}$ (satd.) $\| \mathrm{Eu}^{3+}$ sample solution | ion selective membrane | graphite bar}

The performance of each electrode was investigated by measuring the potential of $\mathrm{Eu}^{3+}$ solutions with concentrations ranging from $1.0 \times 10^{-8}$ to $1.0 \times 10^{-1} \mathrm{M}$ by serial dilution of the $0.1 \mathrm{M}$ stock solution. The potential readings recorded when a steady state value was attained. The observed potential versus the logarithm of the $\mathrm{Eu}^{3+}$ ion concentration was plotted. The $\mathrm{pH}$ of the solutions was measured by a conventional glass $\mathrm{pH}$ electrode.

\section{RESULTS AND DISCUSSION}

\section{Composition and characteristics of the sensors}

As in preparation of many ion selective electrodes a plasticizer/PVC ratio of about 2 has resulted in very appropriate performance characteristics, this ratio was kept in optimization of the ingredients of the $\mathrm{Eu}^{3+}$ coated graphite sensor proposed (Table 1). Since the nature of the plasticizer influences the dielectric constant of the membrane phase and the mobility of the ionophore molecules and the state of ligands, it was expected 
to play a key role in determining the ion-selective characteristics. $^{13}$ As is obvious from Table 1, among four different plasticizers used in preparation of ion-selective sensors (DOP, DBP, NB and DOS), DOS was found to give the best slope and widest linear range of the sensor based on ligand kryptofix 21.

Although neutral carrier based coated graphite membrane electrodes may work properly even when they contain only a very small amount of ionic sites (e.g., as impurities), the addition of a salt of lipophilic ion is advisable and beneficial for various other reasons as well. In fact, it has been demonstrated that the presence of lipophilic negatively charged additives improves the potentiometric behavior of certain cation-selective electrodes by reducing the ohmic resistance and improving the response behavior and selectivity and, in some cases, by catalyzing the exchange kinetics at the sample-membrane interface. ${ }^{14-16}$
From the data presented in Table 1, it is seen that the addition of NaTPB will increase the response slope of the sensor considerably. Use of $2.0 \%(\mathrm{w} / \mathrm{w})$ NaTPB resulted in a Nernstian behavior of the electrode (No. 9). Moreover, $7.0 \%$ (w/w) of kryptofix 21 ionophore was chosen as the optimum amount of ionophore in the PVC membrane (No. 9).

Thus, the results indicate that the best sensitivity and linear range are obtained for membrane No. 9 with kryptofix 21:PVC:NaTPB:DOS weight percent ratio of 7.0:30.0:2.0:61.0. This sensor exhibited a linear response over a wide concentration range of $1.0 \times 10^{-6}$ to $1.0 \times 10^{-1} \mathrm{M}$ and a Nernstian slope of $21.8 \pm 0.1 \mathrm{mV} /$ decade. Hence, it was chosen for further studies. The calibration curve for this sensor is shown in Fig. 2. The limit of detection, as determined from the intersection of the two extrapolated segments of the calibration graph, was $8.2 \times 10^{-7} \mathrm{M}$.

Table 1

Optimization of the $\mathrm{Eu}^{3+}$ selective membrane ingredients

\begin{tabular}{|c|c|c|c|c|c|c|}
\hline \multirow{2}{*}{$\begin{array}{c}\text { Membrane } \\
\text { no. }\end{array}$} & \multicolumn{4}{|c|}{ Membrane mass composition (\%) } & \multirow{2}{*}{$\begin{array}{c}\text { Slope } \\
\text { (mV/decade) }\end{array}$} & \multirow{2}{*}{$\begin{array}{c}\text { Linear } \\
\text { range }(M\end{array}$} \\
\hline & PVC & $\begin{array}{c}\text { Ionophore } \\
\text { (Kryptofix 21) }\end{array}$ & $\begin{array}{l}\text { Additive } \\
\text { (NaTPB) }\end{array}$ & Plasticizer & & \\
\hline 1 & 30 & 9.0 & - & 61.0 (DOS) & $15.2 \pm 1.0$ & $10^{-4}-10^{-1}$ \\
\hline 2 & 30 & - & 9.0 & $61.0(\mathrm{DOS})$ & $12.5 \pm 1.5$ & $10^{-8}-10^{-6}$ \\
\hline 3 & 30 & 5.0 & 2.0 & 63.0 (DOP) & $26.2 \pm 0.2$ & $10^{-5}-10^{-1}$ \\
\hline 4 & 30 & 5.0 & 2.0 & 63.0 (DOS) & $18.3 \pm 0.5$ & $10^{-6}-10^{-2}$ \\
\hline 5 & 30 & 5.0 & 2.0 & 63.0 (DBP) & $23.6 \pm 0.6$ & $10^{-6}-10^{-2}$ \\
\hline 6 & 30 & 5.0 & 2.0 & $63.0(\mathrm{NB})$ & $13.9 \pm 0.2$ & $10^{-5}-10^{-2}$ \\
\hline 7 & 30 & 5.0 & 1.0 & 64.0 (DOP) & $13.4 \pm 0.1$ & $10^{-6}-10^{-1}$ \\
\hline 8 & 30 & 5.0 & 3.0 & $62.0(\mathrm{DBP})$ & $24.1 \pm 0.3$ & $10^{-8}-10^{-4}$ \\
\hline 9 & 30 & 7.0 & 2.0 & 61.0 (DOS) & $21.8 \pm 0.1$ & $10^{-6}-10^{-1}$ \\
\hline 10 & 30 & 7.0 & 2.0 & $61.0(\mathrm{NB})$ & $12.5 \pm 0.7$ & $10^{-5}-10^{-1}$ \\
\hline 11 & 30 & 6.0 & 3.0 & 61.0 (DOP) & $16.4 \pm 1.2$ & $10^{-6}-10^{-3}$ \\
\hline 12 & 30 & 5.0 & 1.0 & 64.0 (DBP) & $22.8 \pm 0.2$ & $10^{-5}-10^{-1}$ \\
\hline 13 & 30 & 6.0 & 2.0 & $62.0(\mathrm{DOS})$ & $17.0 \pm 0.6$ & $10^{-4}-10^{-1}$ \\
\hline 14 & 30 & 5.0 & 1.0 & $64.0(\mathrm{NB})$ & $16.5 \pm 0.1$ & $10^{-7}-10^{-3}$ \\
\hline 15 & 30 & 7.0 & 2.0 & 61.0 (DBP) & $25.0 \pm 0.3$ & $10^{-5}-10^{-1}$ \\
\hline
\end{tabular}




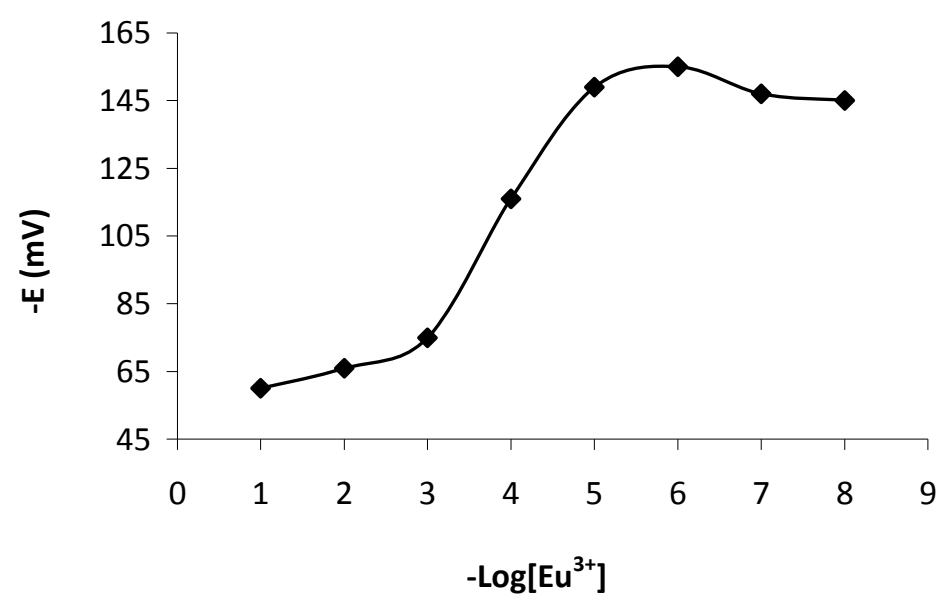

Fig. 2 - Calibration curve of the $\mathrm{Eu}^{3+}$ selective sensor based on kryptofix 21.

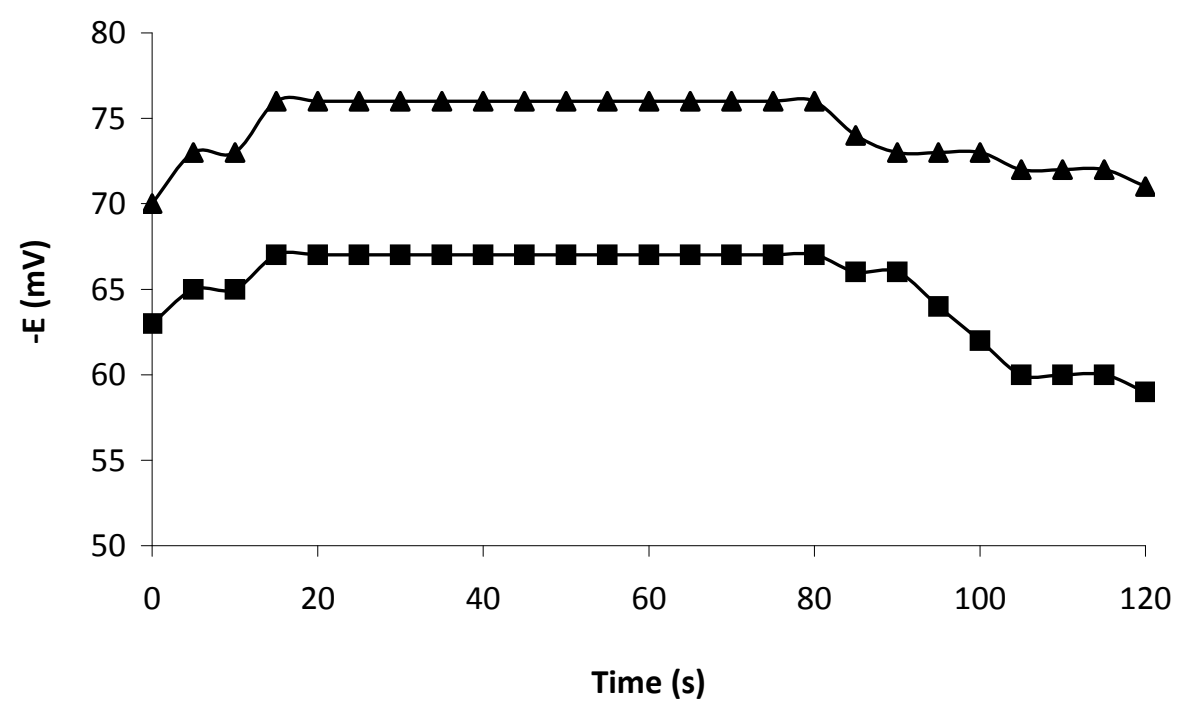

Fig. 3 - Static response time curves of the $\mathrm{Eu}^{3+}$ selective sensor $\left(\boldsymbol{\bullet} 1.0 \times 10^{-2} \mathrm{M}, \boldsymbol{\Delta} 1.0 \times 10^{-3} \mathrm{M}\right)$.

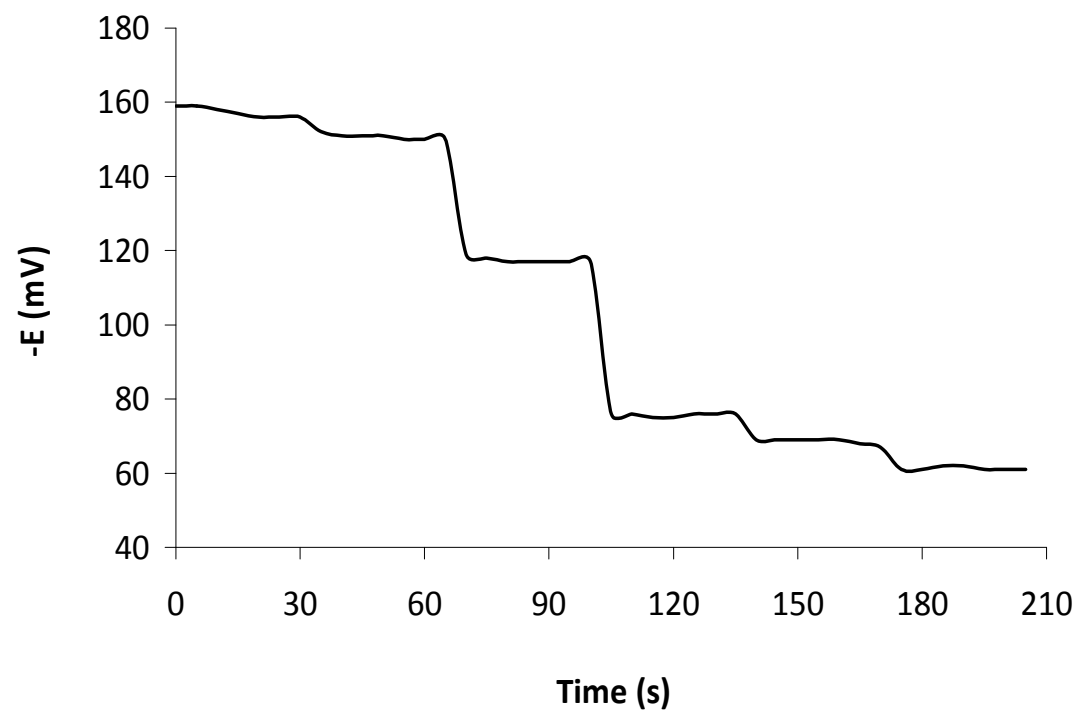

Fig. 4 - Dynamic response time of the $\mathrm{Eu}^{3+}$ selective sensor for step changes in the concentration range of $1.0 \times 10^{-6} \mathrm{M}$ to $1.0 \times 10^{-1} \mathrm{M}$. 


\section{Response time and reversibility}

Static response time is an important factor for the assessment of the analytical applicability of ion selective sensors. For potentiometric sensors, this parameter is evaluated by measuring the average time required to achieve a potential within $90 \%$ of the final steady state potential upon successive immersion of a series of interested ions, each having a ten-fold difference in concentration. Experimental conditions such as ionic concentration and composition of the test solution, the concentration and composition of the solution to which the electrode was exposed before performing the experiment measurement, any previous usage or preconditioning of the electrode, and the testing temperature can all affect the experimental response time of a sensor. In the present study, the static response time was recorded (for sensor No. 9) by plotting the potential response vs. time, at $1.0 \times 10^{-3} \mathrm{M}$ and $1.0 \times 10^{-2} \mathrm{M}$ of $\mathrm{Eu}^{3+}$ ion solutions (Fig. 3). As shown in this figure, throughout the entire concentration range, the sensor reaches equilibrium in a short period of time ( $15 \mathrm{~s})$ and potentials stay constant for $80 \mathrm{~s}$. This behavior can be due to the fast exchange kinetics of the complexationdecomplexation of Eu (III) cations with the ion carrier at the test solution-membrane interface.

Dynamic response time is another very important factor in the evaluation of any sensor. The practical response time is practically recorded by varying standard test solutions with different target ion concentrations. The measurement sequence is from the lower $\left(1.0 \times 10^{-6} \mathrm{M}\right)$ to the higher $\left(1.0 \times 10^{-1} \mathrm{M}\right)$ concentration of Eu (III). The dynamic response time for sensor No. 9 is shown in Fig. 4. As it is seen, the sensor reaches the equilibrium response in a short time of about $15 \mathrm{~s}$.
To evaluate the reversibility of the proposed sensor (No. 9), a similar procedure can also be adopted. The measurements are performed in the sequence of low-to-high (from $1.0 \times 10^{-4}$ to $1.0 \times$ $10^{-3} \mathrm{M}$ ) sample concentrations. The results show that, the potentiometric response of the sensor is reversible (Fig. 5). The sensing behavior of the electrode remained unchanged when the potentials recorded either from high-to-low concentrations or vice versa.

\section{Effect of pH}

Effect of $\mathrm{pH}$ on the response of sensor No. 9 was studied over two different concentrations $\left(1.0 \times 10^{-3} \mathrm{M}\right.$ and $\left.1.0 \times 10^{-2} \mathrm{M}\right)$ of $\mathrm{Eu}^{3+}$ ions. Studies were carried out over a $\mathrm{pH}$ range of 1-14. Introducing $\mathrm{HNO}_{3}$ or $\mathrm{NaOH}$ drop wise adjusted the $\mathrm{pH}$ and the results are shown in Fig. 6. The potential difference is independent of $\mathrm{pH}$ in the range 2-12. Therefore, this can be taken as the working $\mathrm{pH}$ range for the proposed sensor system. Since at $\mathrm{pH}$ value lower than 2 , a decrease in potential is observed, probably the electrode starts responding to $\mathrm{H}^{+}$ions. At $\mathrm{pH}$ greater than 12 , the deviation can be assigned to the formation of some hydroxyl complexes of $\mathrm{Eu}$ (III) ions.

\section{Lifetime and stability}

For studying the lifetime and stability of the proposed sensor, three similar membrane sensors were chosen, and their slopes were recorded during 10 weeks. The corresponding results are given in Table 2. According to this Table, the Eu (III) sensor could be used for 8 weeks without any significant change in its slope. After the end of the time period, a decrease in the slope (from 18.7 to $16.3 \mathrm{mV} /$ decade) was observed.

Table 2

Lifetime of the $\mathrm{Eu}^{3+}$ selective sensor

\begin{tabular}{ccc}
\hline Period (weeks) & Slope $(\mathbf{m V} /$ decade) & Linear concentration range (M) \\
\hline 1 & $21.8 \pm 0.1$ & $10^{-6}-10^{-1}$ \\
2 & $21.3 \pm 0.2$ & $10^{-6}-10^{-1}$ \\
3 & $21.1 \pm 0.3$ & $10^{-6}-10^{-1}$ \\
4 & $20.9 \pm 0.3$ & $10^{-6}-10^{-1}$ \\
5 & $20.0 \pm 0.2$ & $10^{-6}-10^{-1}$ \\
6 & $19.5 \pm 0.1$ & $10^{-6}-10^{-1}$ \\
7 & $19.2 \pm 0.2$ & $10^{-6}-10^{-1}$ \\
8 & $18.7 \pm 0.4$ & $10^{-6}-10^{-1}$ \\
9 & $16.3 \pm 0.5$ & $10^{-5}-10^{-1}$ \\
10 & $15.5 \pm 0.3$ & $10^{-5}-10^{-1}$ \\
\hline
\end{tabular}




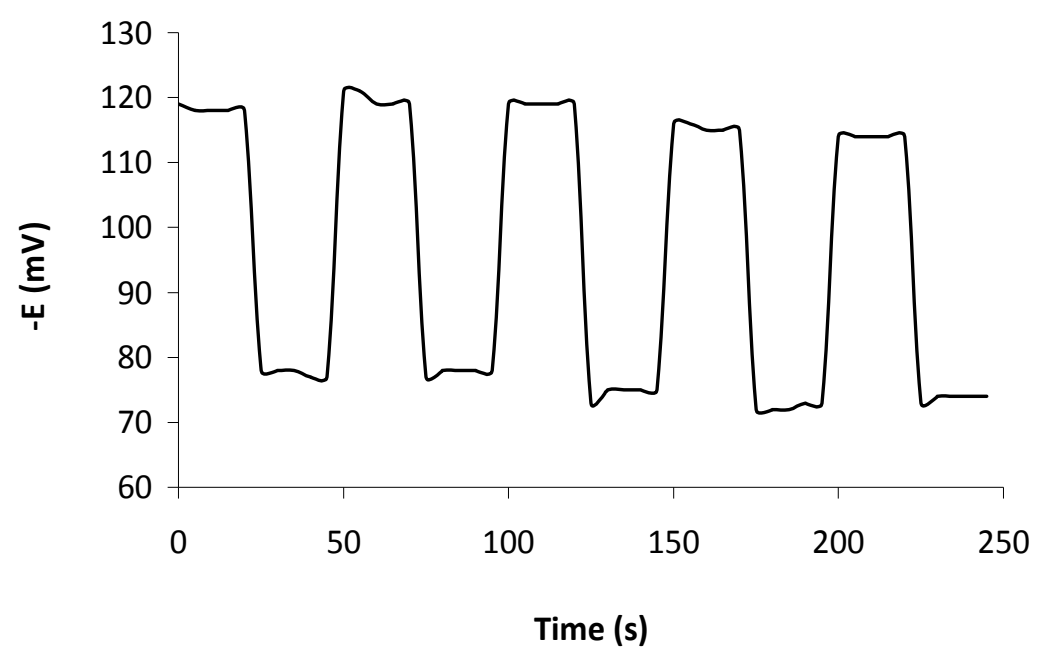

Fig. 5 - Reversibility of the $\mathrm{Eu}^{3+}$ selective sensor for several low-to-high $\left(1.0 \times 10^{-4}\right.$ to $\left.1.0 \times 10^{-3} \mathrm{M}\right)$ sample cycles.

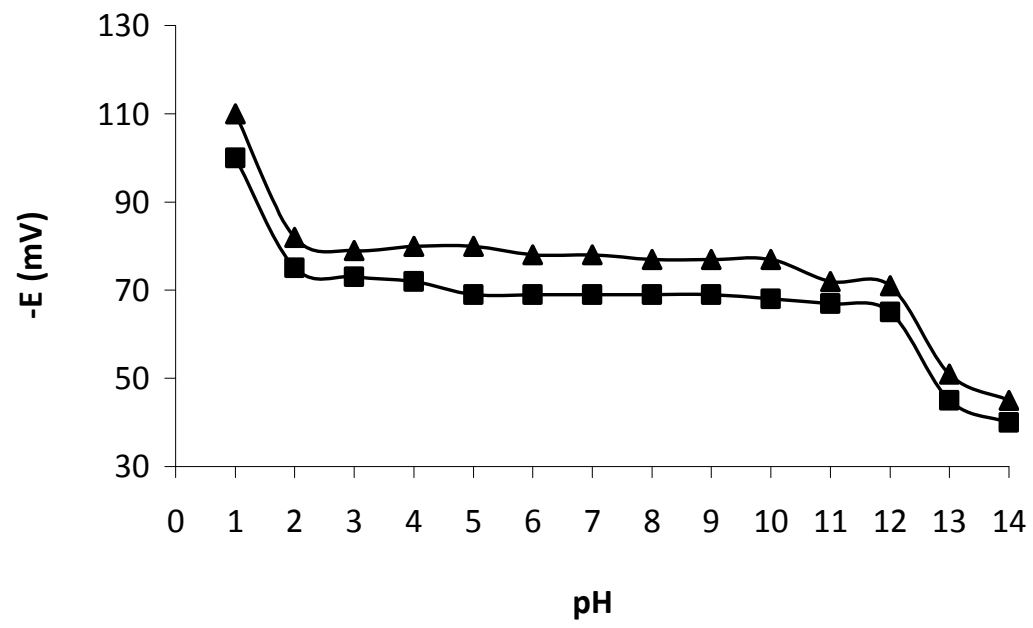

Fig. 6 - Effect of the $\mathrm{pH}$ of test solutions on potential response of the $\mathrm{Eu}^{3+}$ selective sensor $\left(\boldsymbol{\square} 1.0 \times 10^{-2} \mathrm{M}, \boldsymbol{\Delta} 1.0 \times 10^{-3} \mathrm{M}\right)$.

\section{Potentiometric selectivity}

The effect of interfering ions on the response behavior of Eu (III) sensor based on kryptofix21, known as potentiometric selectivity coefficients $\left(K_{E v u_{j}}^{p o t}\right)$, was evaluated by separate solution method (SSM) ${ }^{17-19}$ In this study, respective nitrate salts at $1.0 \times 10^{-2} \mathrm{M}$ concentration was used and $K^{p o t}{ }_{E u, j}$ was then calculated from the two observed potential values according to the following equation:

$$
\log K_{i j}^{p o t}=\frac{E j-E i}{2.303 R T / z i F}+\left(1-z_{i} / z_{j}\right) \log a_{i}
$$

where $E_{i}$ and $E_{j}$ are the measured potentials of primary $\left(\mathrm{Eu}^{3+}\right)$ and interfering ions and $z_{i}$ and $z_{j}$ are their respective charges. The $K_{E u, j}^{p o t}$ of mono-, di- and trivalent cations were measured (Table 3). The results in this Table indicate that sensor No. 9 is selective for $\mathrm{Eu}$ (III) ion in the presence of interfering ions. As seen for most ions used, $K_{E u, j}^{p o t}$ values were of the order of $10^{-3}$ or smaller, indicating that they would not significantly disturb the functioning of the $\mathrm{Eu}$ (III) ion-selective electrode. Hence, these cations are not expected to interfere with the functioning of the proposed sensor even at high concentration levels.

\section{Analytical applications}

The proposed sensor was successfully applied as an indicator electrode in potentiometric titration of $\mathrm{Eu}^{3+}$ solutions with EDTA. $1.0 \times 10^{-4} \mathrm{M}$ and $1.0 \times 10^{-3} \mathrm{M}$ of $\mathrm{Eu}^{3+}$ solutions of $25.0 \mathrm{~mL}$ were 
titrated with $1.0 \times 10^{-3} \mathrm{M}$ and $1.0 \times 10^{-2} \mathrm{M}$ solutions of EDTA, respectively. The resulting titration curves are shown in Figs. 7 and 8. As can be seen, the amount of $\mathrm{Eu}^{3+}$ ions in solution can be determined with the electrode. The observation of titration curve is due to the fact that, before the end point, the potential showed a usual decreasing change with the volume of titrant added, while the potential response after the end point remained almost constant, due to the low concentration of free $\mathrm{Eu}^{3+}$ in solution. ${ }^{20}$

To assess the applicability of the proposed sensor in real samples an attempt was made to determine europium in tap water, river water, milk and apple juice samples. The results are given in
Table 4. As is obvious, quantitative recovery of Eu (III) from different samples is achievable.

\section{Comparison with other $\mathrm{Eu}^{3+}$ sensors}

Finally, a comparison with other $\mathrm{Eu}^{3+}$ selective sensors based on various ionophores reported in the literatures was made. Table 5 presents the main analytical characters of some europium (III) selective electrodes. The proposed sensor based on kryptofix 21 ionophore exhibits either comparable or better performance to the existing electrodes such as detection limit, $\mathrm{pH}$ range and linear concentration range. Therefore, the proposed sensor is a good addition to the existing list of the $\mathrm{Eu}$ (III) ion selective sensors reported till date.

Table 3

Selectivity coefficients of various interfering ions for $\mathrm{Eu}^{3+}$ selective sensor

\begin{tabular}{cc}
\hline Interfering ions & Selectivity coefficients $\left(\boldsymbol{K}_{\boldsymbol{E}, \boldsymbol{j}, \boldsymbol{j}}^{\text {pot }}\right)$ \\
\hline $\mathrm{K}^{+}$ & $4.3 \times 10^{-6}$ \\
$\mathrm{Ag}^{+}$ & $<10^{-6}$ \\
$\mathrm{Ni}^{2+}$ & $3.4 \times 10^{-5}$ \\
$\mathrm{~Pb}^{2+}$ & $<10^{-6}$ \\
$\mathrm{Cu}^{2+}$ & $1.1 \times 10^{-4}$ \\
$\mathrm{Cd}^{2+}$ & $1.3 \times 10^{-3}$ \\
$\mathrm{Sr}^{2+}$ & $8.9 \times 10^{-6}$ \\
$\mathrm{Fe}^{3+}$ & $6.7 \times 10^{-3}$ \\
$\mathrm{Cr}^{3+}$ & $1.6 \times 10^{-5}$ \\
$\mathrm{Ce}^{3+}$ & $<10^{-6}$ \\
\hline
\end{tabular}

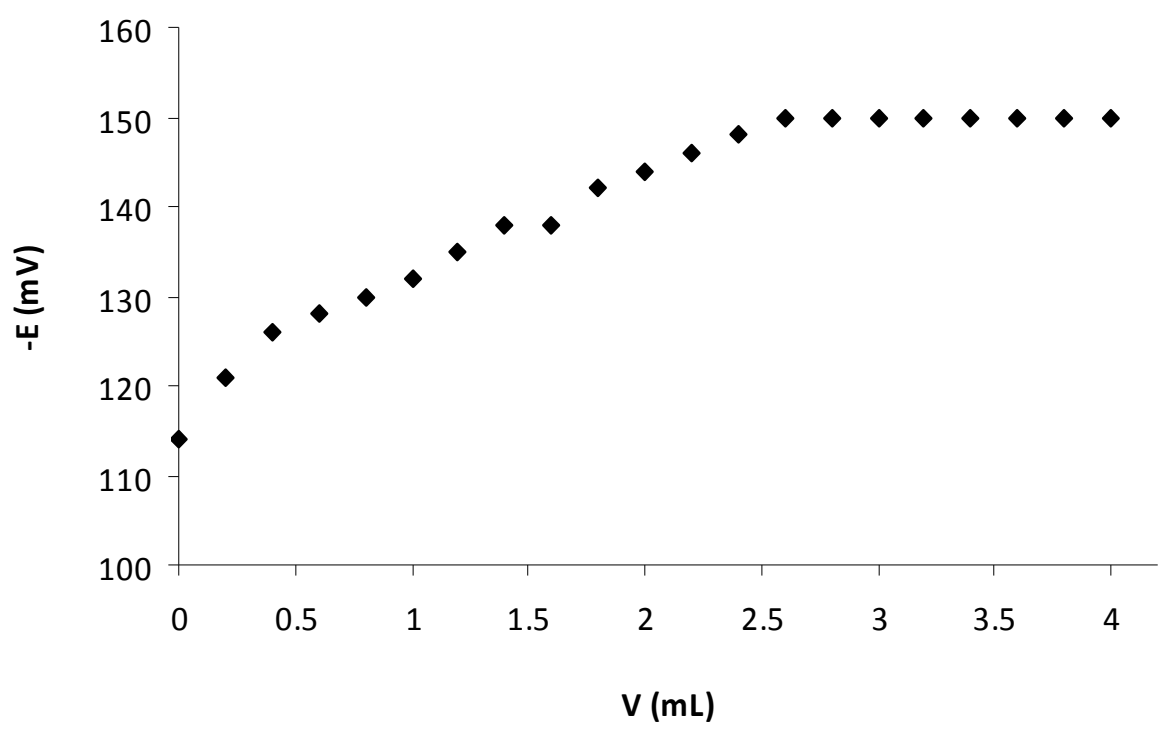

Fig. 7 - Potentiometric titration curve for $25 \mathrm{~mL} 1.0 \times 10^{-4} \mathrm{M}$ of $\mathrm{Eu}^{3+}$ solution with $1.0 \times 10^{-3} \mathrm{M}$ of EDTA. 


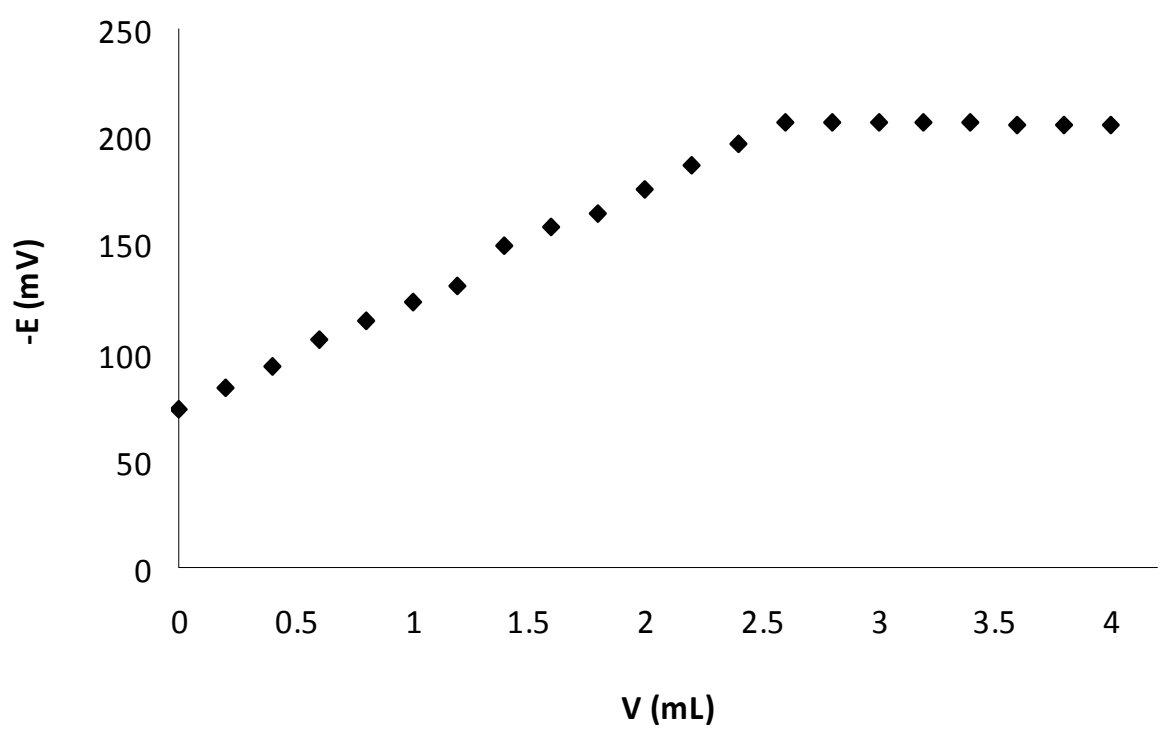

Fig. 8 - Potentiometric titration curve for $25 \mathrm{~mL} 1.0 \times 10^{-3} \mathrm{M}$ of $\mathrm{Eu}^{3+}$ solution with $1.0 \times 10^{-2} \mathrm{M}$ of EDTA.

Table 4

Potentiometric determination of $\mathrm{Eu}^{3+}$ ion in different real samples using the $\mathrm{Eu}^{3+}$ selective sensor

\begin{tabular}{|c|c|c|c|}
\hline Real samples & $\begin{array}{l}\text { Added } \mathrm{Eu}^{3+} \\
\text { concentration } \\
\text { (M) }\end{array}$ & $\begin{array}{l}\text { Found } \mathrm{Eu}^{3+} \\
\text { concentration } \\
\text { (M) }\end{array}$ & Recovery (\%) \\
\hline $\begin{array}{c}\text { Tap water } \\
\text { (Ahvaz city, Iran) }\end{array}$ & $3.0 \times 10^{-4}$ & $2.8 \times 10^{-4}$ & 93.3 \\
\hline $\begin{array}{c}\text { River water } \\
\text { (Karoon river, Iran) }\end{array}$ & $3.0 \times 10^{-4}$ & $2.9 \times 10^{-4}$ & 96.6 \\
\hline Milk & $3.0 \times 10^{-4}$ & $2.7 \times 10^{-4}$ & 90.0 \\
\hline Apple juice & $3.0 \times 10^{-4}$ & $2.7 \times 10^{-4}$ & 90.0 \\
\hline
\end{tabular}

Table 5

Comparison of the characteristics of the proposed optimum sensor with those of the previously reported $\mathrm{Eu}^{3+}$ sensors

\begin{tabular}{|c|c|c|c|c|c|c|}
\hline Ionophore & $\begin{array}{l}\text { Detectin } \\
\text { limit (M) }\end{array}$ & $\begin{array}{c}\text { Slope } \\
\text { (mV/decade) }\end{array}$ & $\begin{array}{c}\mathrm{pH} \\
\text { range }\end{array}$ & $\begin{array}{c}\text { Linear concentration } \\
\text { range }(M)\end{array}$ & $\begin{array}{c}\text { Response } \\
\text { time (s) }\end{array}$ & Ref. no \\
\hline $\begin{array}{l}\text { bis(thiophenol)butane2,3- } \\
\text { dihydrazone (SNSB) }\end{array}$ & $5.0 \times 10^{-6}$ & $19.7 \pm 0.2$ & $3.0-8.5$ & $1.0 \times 10^{-5}-1.0 \times 10^{-2}$ & $<5$ & [21] \\
\hline $\begin{array}{l}\text { N-pyridine-2-carboxamido-8- } \\
\text { aminoquinoline (PCQ) }\end{array}$ & $6.4 \times 10^{-7}$ & $19.8 \pm 0.3$ & $2.4-7.4$ & $1.0 \times 10^{-6}-1.0 \times 10^{-2}$ & 10 & {$[22]$} \\
\hline $\begin{array}{l}\text { (2-((2-phenyl-2-(pyridin-2- } \\
\text { yl)hydazono)methyl)pyridine) } \\
{\left[\mathrm{L}_{1}\right] \text { and }(2-((2-\text { phenyl-2- }} \\
\text { (pyridin-2-yl)hydazono) } \\
\text { methyl)phenol) }\left[\mathrm{L}_{2}\right]\end{array}$ & - & - & $2.7-9.0$ & - & 10 & {$[23]$} \\
\hline $\begin{array}{c}\text { N-pivot diglycolamide } \\
\text { (diglycolamide-TREN (TREN- } \\
\text { DGA) }\end{array}$ & - & $17.2 \pm 0.4$ & - & $3.2 \times 10^{-7}-1.0 \times 10^{-2}$ & - & {$[24]$} \\
\hline $\begin{array}{c}\mathrm{N}, \mathrm{N}, \mathrm{N}^{\prime}, \mathrm{N}^{\prime} \text {-tetraoctyl } \\
\text { diglycolamide (TODGA) }\end{array}$ & $1.2 \times 10^{-6}$ & $17.3 \pm 0.1$ & - & $1.5 \times 10^{-6}-1.2 \times 10^{-2}$ & $<10$ & [25] \\
\hline Kryptofix 21 & $8.2 \times 10^{-7}$ & $21.8 \pm 0.1$ & $2.0-12.0$ & $1.0 \times 10^{-6}-1.0 \times 10^{-1}$ & 15 & $\begin{array}{l}\text { [This } \\
\text { work] }\end{array}$ \\
\hline
\end{tabular}




\section{CONCLUSION}

In the present study, kryptofix 21 as a selective and sensitive material has been used successfully to develop $\mathrm{Eu}$ (III)-selective sensor with a wide concentration range of $1.0 \times 10^{-6}$ to $1.0 \times 10^{-1} \mathrm{M}$ and Nernstian slope of $21.8 \pm 0.1 \mathrm{mV} / \mathrm{dec}$ de. Meanwhile, it has some other advantages, such as fast response time, wide $\mathrm{pH}$ range, fine selectivity and long lifetime. Moreover, it was successfully applied as an indicator electrode to the europium ions titration with EDTA as well as to the $\mathrm{Eu}^{3+}$ ions detection in different real samples. These characters make us believe that the proposed sensor will be used widely.

Acknowledgements. The authors wish to thank the Ahvaz Branch, Islamic Azad University for the financial support. The authors would like to thank all the editors and reviewers for their comments in the development and improvement of this paper.

\section{REFERENCES}

1. K. A. Gschneidner and L. Eyring, "Handbook on the Physics and Chemistry of the Rare Earths", vol. 1, North Holand Publishing Co. Amsterdam, 1979.

2. O. R. Kirk and F. D. Othmer, "Encyclopedia of Chemical Technology", vol. 19, Wiley, 1982, p. 851.

3. V. K. Gupta, A. K. Jain, P. Kumar1, S. Agarwal and G. Maheshwari, Sens. Actuators B, 2006, 113, 182-186.

4. Y. H. Ma, R. Yuan, Y. Q. Chai and X. L. Liu, Mater. Sci. Eng. C, 2010, 30, 209-213.

5. G. H. Rounaghi and A. Ghaemi, J. Electrochem. Soc., 2012, 159, F97-F102

6. A. Ghaemi, H. Tavakkoli and T. Mombeni, Mater. Sci. Eng. C, 2014, 38, 186-191.
7. M. Kumar Sahani, S. Bhardwaj and A. K. Singh, J. Electroanal. Chem., 2016, 780, 209-216.

8. K. Girish Kumar, P. Augustine, S. John, J. Radecki and H. Radecka, Anal. Lett., 2008, 41, 1144-1157.

9. G. Rounaghi, R. Mohammad Zadeh Kakhki and H. Sadeghian, Electrochim. Acta, 2011, 56, 9756-9761.

10. Y. Fan, C. Xu, R. Wang, G. Hu, J. Miao, K. Hai and C. Lin, J. Food Comp. Anal., 2017, 62, 63-68.

11. J. He, Y. Li, X. Xue, H. Ru, X. Huang and H. Yang, J. Rare Earths, 2017, 35, 934-940.

12. J. Wan, W. Duan, K. Chen, Y. Tao, J. Dang, K. Zeng, Y. Ge, J. Wu and D. Liu, Sens. Actuators B, 2018, 255, 49-56.

13. I. Svancara, K. Vytras, J. Barek and J. Zima, Crit. Rev., 2001, 31, 311-346.

14. R. Eugster, P. M. Gehring, W. E. Morf, U. E. Spichiger and W. Anal. Chem., 1991, 63, 2285-2289.

15. U. Schaller, E. Bakker, U. E. Spichiger and E. Pretsch, Anal. Chem., 1994, 66, 391-398.

16. P. M. Gehring, W. E. Morf, M. Welti, E. Pretsch and W. Simon, Helv. Chim. Acta, 1990, 73, 203-212.

17. E. Bakker, P. Buhlmann and E. Pretsch, Chem. Rev., 1997, 97, 3083-3132.

18. Y. Umezawa, K. Umezawa and H. Sato, Pure Appl. Chem., 1995, 67, 507-518.

19. Y. Umezawa, P. Buhlmann, K. Umezawa, K. Tohda and S. Amemiya, Pure Appl. Chem., 2000, 72, 1851-2082.

20. M. Mazloum, M. K. Amini, I. Mohammad and P. Baltork, Sens. Actuators B, 2000, 63, 80-85.

21. M. R. Ganjali, P. Norouzi, A. Daftari, F. Faridbod and M. Salavati-Niasari, Sens. Actuators B, 2007, 120, 673-678.

22. H. A. Zamani, R. Kamjoo, M. Mohammadhosseini, M. Zaferoni, Z. Rafati, M. R. Ganjali, F, Faridbod and S. Meghdadi, Mater. Sci. Eng. C, 2012, 32, 447-451.

23. A. Upadhyay, A. K. Singh, K. R. Bandi and A. K. Jain, Talanta, 2013, 115, 569-576.

24. B. Mahanty, A. K. Satpati, S. Kumar, A. Leoncini, J. Huskens, W. Verboom and P. K. Mohapatra, Sens. Actuators B, 2018, 272, 534-542.

25. B. Mahanty, A. K. Satpati and P. K. Mohapatra, J. Electroanal. Chem., 2018, 808, 340-347. 
